\title{
Towards Integration and Impact: Clinical Psychology Takes Action for Mental Health in Europe
}

\author{
Tanja Endrass ${ }^{\text {a }}$, Philipp Kanske ${ }^{\text {ab }}$
}

[a] Institute of Clinical Psychology and Psychotherapy, Faculty of Psychology, Technische Universität Dresden, Dresden, Germany. [b] Max Planck Institute for Human Cognitive and Brain Sciences, Leipzig, Germany.

Clinical Psychology in Europe, 2019, Vol. 1(4), Article e49194, https://doi.org/10.32872/cpe.v1i4.49194

Published (VoR): 2019-12-17

Corresponding Author: Tanja Endrass, Technische Universität Dresden, Faculty of Psychology, Insititute of Clinical Psychology and Psychotherapy, Chair of Addiction Research, 01062 Dresden, Germany. Phone +49 351463 32460, Fax +49351 463 39830. E-mail: tanja.endrass@tu-dresden.de

From October 31 to November 2, 2019, the first conference of the new European Association of Clinical Psychology and Psychological Treatment (EACLIPT) took place at Technische Universität Dresden, Germany (Beesdo-Baum et al., 2019). It was a historic moment that brought together clinical psychologists from many different regions of the world. About 300 researchers and psychotherapists discussed the most recent developments in clinical psychology, possibilities for outreach, collaboration across countries, improvement of therapy delivery and the science-policy dialogue. With their inspiring presentations, they brought to life one of the main goals of EACLIPT: fostering exchange among clinical psychologists from all over Europe (Andersson, 2019). The five renowned keynote speakers reflected the diversity of topics at \#EACLIPT2019: Claudi Bockting (University of Amsterdam) called for more engagement with European politicians to raise awareness for mental health and the efficacy of psychological treatments. Presenting the Improving Access to Psychological Therapies program (IAPT; Clark, 2018), David Clark (University of Oxford) demonstrated that such engagement can be extremely fruitful. New developments in psychotherapy were presented by Susan Bögels (University of Amsterdam) on mindfulness in families and by Maria Karekla (University of Cyprus) on e-mental-health tools. Stefan Hofmann (Boston University) integrated different novel approaches in his talk on Modern Process-based Cognitive Behavioral Therapy.

The scientific program included symposia and posters on novel developments in the field of mechanisms underlying mental disorders, epidemiology, prevention, diagnostics, psychotherapeutic treatment, and methods. Thus, the full spectrum of clinical psychology and psychological intervention was represented at the conference. The program also 
included three stimulating panel discussions on current topics of clinical psychology. The first discussion addressed the theme of the conference "No Health without Mental Health" and focused on how to move forward in research as well as on how clinical psychology can contribute to European initiatives. The discussion on "Psychotherapy and Psychotherapy Training across Europe" addressed the problem of immense heterogeneity in national regulations of clinical psychology and psychological treatment. The differences across European countries pose problems for collaborative research initiatives and exchange in education; potential solutions were discussed (Laireiter \& Weise, 2019). "Challenges and Innovations for Psychotherapy" was the topic of the final panel which focused on transdiagnostic research strategies as well as new innovative mechanismbased interventions and online therapies. Although we can only transmit a brief idea of the rich panel discussions, we can subsume that they covered highly relevant topics and stimulated reflections about the current situation in clinical psychology, and brought together knowledge, experiences and insights into future perspectives by professionals from diverse fields and different countries.

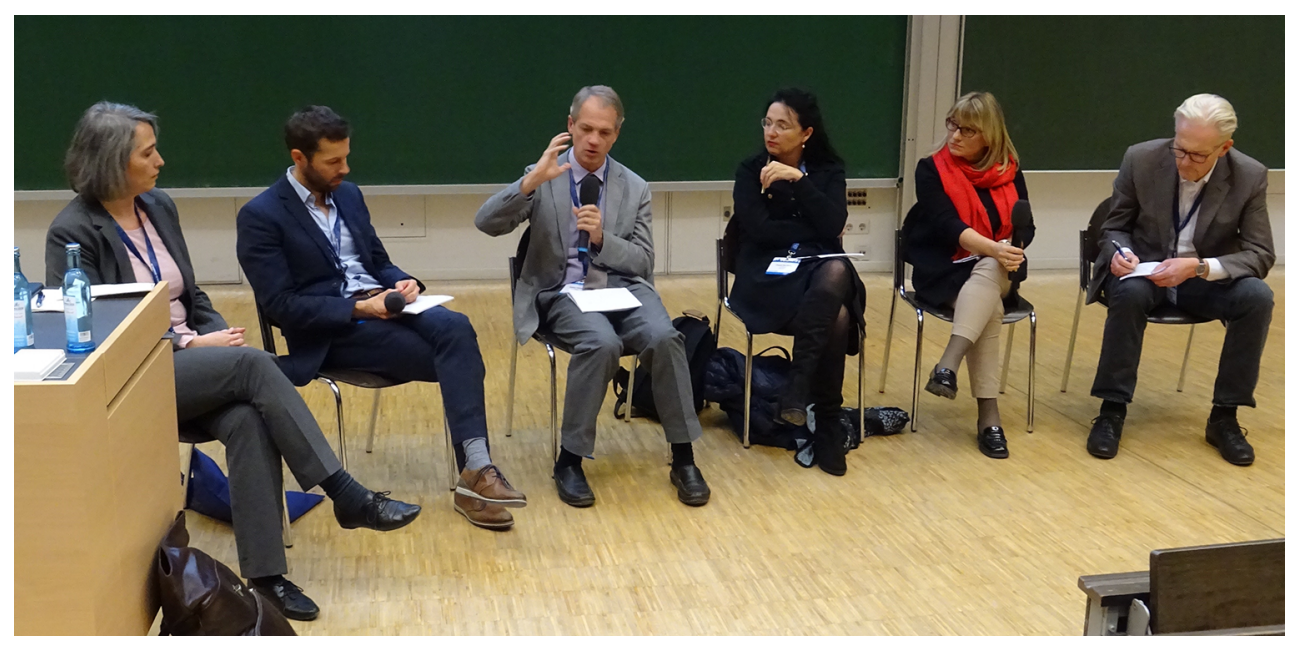

Figure 1. Panel Discussion "No health without mental health", Discussants: Tanja Endrass, Philipp Kanske, Stefan Hofmann, Claudi Bockting, Agnieszka Popiel, Martin grosse Holtforth. Photo and copyright by Michael Höfler, published under a CC-BY 4.0 license.

Besides the official scientific program, additional pre- and post-conference workshops were held on "Psychopathology and the Social Brain" (Philipp Kanske and Jan Haaker, funded by Die Junge Akademie), "Suicide Prevention in Germany” (Susanne Knappe, funded by the Federal Ministry for Health), "Ubiquity - New Perspectives on Experienced Traumata” (Philipp Kanske and Miriam Akkermann, funded by Die Junge Akademie), and an Early Career Research Workshop (Lara Maliske and Susanne Knappe, supported 
by Springer Nature). During the members meeting, Claudi Bockting was elected as the new president of EACLIPT. With her motivation for more political engagement she will push for increasing awareness for mental health at the European level. Finally, we would like to highlight the great posters presented at the conference and congratulate the two young researchers who were awarded the first EACLIPT poster prize: Marie-Christin Atzor (Poster title: "Tell me something good! The influence of experience reports on attitude towards psychotherapy”, University of Marburg, Germany) and Marike van Vugt (Poster title: "Using computational process of depressive rumination to predict cognitive deficits”, University of Groningen, Netherlands; funded by Wiley).

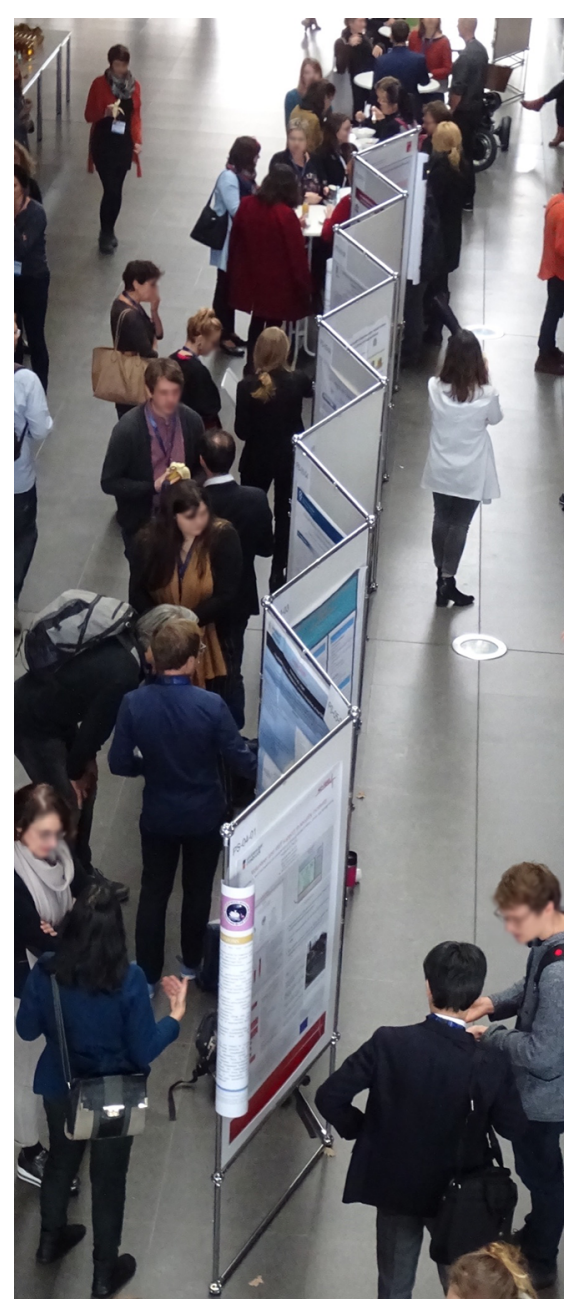

Figure 2. Postersession at the EACLIPT conference. 
Beyond these specific events, most participants will keep a great memory of the stimulating and warm ambience of this meeting. People were standing together, engaged in communication and exchanging ideas, and new projects and collaborations were started. Finally, the conference would not have been possible without the great help of our colleagues in the organizing team, Hannah Niermann, Katja Beesdo-Baum, Jürgen Hoyer, and Corinna Jacobi, as well as many other contributors and everyone, who presented their work, making the conference a fantastic start for now yearly meetings of EACLIPT.

Funding: Financial support for the conference was granted by the German Academic Exchange Service, the German Research Foundation, and the Technische Universität Dresden.

\section{References}

Andersson, G. (2019). The European Association of Clinical Psychology and Psychological Treatment (EACLIPT): A new organization for the future! Clinical Psychology in Europe, 1(1), Article e33241. https://doi.org/10.32872/cpe.v1i1.33241

Beesdo-Baum, K., Endrass, T., Hoyer, J., Jacobi, C., \& Kanske, P. (2019). No health without mental health - European clinical psychology takes responsibility. Clinical Psychology in Europe, 1(1), Article e34220. https://doi.org/10.32872/cpe.v1i1.34220

Clark, D. M. (2018). Realizing the mass public benefit of evidence-based psychological therapies: The IAPT program. Annual Review of Clinical Psychology, 14(1), 159-183. https://doi.org/10.1146/annurev-clinpsy-050817-084833

Laireiter, A.-R., \& Weise, C. (2019). The heterogeneity of national regulations in clinical psychology and psychological treatment in Europe. Clinical Psychology in Europe, 1(1), Article 34406. https://doi.org/10.32872/cpe.v1i1.34406

\section{EACLIPT}

Clinical Psychology in Europe (CPE) is the official journal of the European Association of Clinical Psychology and Psychological Treatment (EACLIPT).

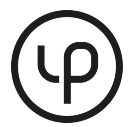

leibniz-psychology.org

PsychOpen GOLD is a publishing service by Leibniz Institute for Psychology Information (ZPID), Germany. 